\title{
Sete poemas de Olav H. Hauge
}

\author{
Guilherme da Silva Braga'
}

\section{Apresentação}

Olav H. Hauge nasceu em 1908 no vilarejo de Ulvik, no oeste da Noruega. Ganhou a vida cultivando maçãs no pequeno terreno que lhe pertencia, porém na aparente simplicidade da vida no campo encontrou a imaginação e a inspiração necessárias não apenas para manter diários ao longo de setenta anos e aprender inglês, alemão e francês bem o suficiente para traduzir os grandes poetas desses idiomas, mas acima de tudo para escrever poemas de características únicas e impressionantes. Ao longo de toda a obra empregou sempre o hognorsk, variante conservadora do norueguês que difere substancialmente do bokmål, forma predominante da língua atual. Teve a obra reconhecida em diversas ocasiões ainda em vida e morreu em 1994, aos 85 anos, sem jamais ter deixado o vilarejo natal.

O poema que me levou a puxar o fio do novelo que compõe a obra de Hauge foi "Lodd" ("Pesos"), que ainda hoje me espanta por dizer tanto com tão pouco. As características desse poema assemelham-se às de outros presentes nessa breve apresentação do poeta norueguês: são obras curtas, quase sempre marcadas por imagens da natureza e de objetos relacionados à lida do campo, que com um

1 Guilherme da Silva Braga é mestre e doutor em Estudos de Literatura pela Universidade Federal do Rio Grande do Sul (Brasil) e concluiu um pós-doutoramento na área de tradução literária na Universidade de Coimbra (Portugal). Traduziu mais de 50 volumes publicados de autores clássicos e contemporâneos a partir do inglês, do norueguês e do sueco para as principais editoras brasileiras. Ministrou oficinas de tradução literária no Brasil, na Irlanda e em Portugal, e em 2016 foi indicado ao Prêmio Jabuti de melhor tradução literária publicada no Brasil. 
giro de frase inesperado passam de um momento para o outro a falar sobre universos inteiros. E nesse ponto me detenho, pois leio e releio esses poemas com o assombro de quem observa um inseto raro e delicado, receoso de tocá-lo para não lhe machucar as patinhas diáfanas.

Os poemas aqui traduzidos perpassam quase toda a carreira de Hauge e foram originalmente publicados nas coletâneas Under bergfallet, de 1951 ("Konkylie" / "Concha"), På ornetuva, de 1961 ("Kom ikkje med heile sanningi" /"Não venha com toda a verdade"), Dropar $i$ austavind, de 1966 ("Yver hengjemyri" /"Travessia do pântano", "Eg stend eg, seddu"/"Eu estou aqui, sabe" e "Lat meg gjera som tordivelen"/“Quero fazer como o rola-bosta"), Spor vinden, de 1971 ("Lodd" /"Pesos") e Janglestrå, de 1980 ("Bruvekti"/"A balança").

\section{Edição consultada:}

HAUGE, Olav H. Dikt i samling. Det Norske Samlaget: Oslo, 1994. 


\begin{tabular}{|l|l|}
\hline Konkylie & Concha \\
Du byggjer di sjel hus. & Você constrói uma casa para a alma. \\
Og du skrid stolt & Então desliza orgulhoso \\
i stjerneljoset & sob a luz das estrelas \\
med huset på ryggen & tendo a casa nas costas \\
liksom snigelen. & como o caracol. \\
Ottast du fåre, & Ao pressentir o perigo, \\
kryp du inn i huset & esconde-se em casa, \\
og er trygg & a salvo \\
bak hardt & por trás da \\
skal. & concha. \\
Og når du ikkje er meir, & E quando você não estiver mais aqui, \\
skal huset & a casa \\
stå att & vai dar \\
og vitna & testemunho \\
um di sjels venleik. & do esplendor de sua alma. \\
Og di einsemds hav & E um mar de solidão \\
skal susa & vai soar \\
der. & lá dentro. \\
& \\
\hline
\end{tabular}




\begin{tabular}{|c|c|}
\hline Lodd & Pesos \\
\hline $\begin{array}{l}\text { Er du med på romferdi, } \\
\text { eller er du } \\
\text { eitt av desse loddi } \\
\text { som stend att på bakken og segjer } \\
\text { dette gjeng aldri i verdi? }\end{array}$ & $\begin{array}{l}\text { Você também está na viagem ao espaço } \\
\text { ou você é } \\
\text { um desses pesos } \\
\text { que permanece no chão e diz, } \\
\text { "Isso nunca vai dar certo"? }\end{array}$ \\
\hline $\begin{array}{l}\text { Det er ingen ting å gjera med lodd. } \\
\text { Dei stend der. } \\
\text { Ein kan vega dei upp, dei } \\
\text { segjer ingen ting um det. } \\
\text { Men dei stend der } \\
\text { like urikkelege, like kalde. }\end{array}$ & $\begin{array}{l}\text { Não há nada o que fazer com pesos. } \\
\text { Eles ficam lá. } \\
\text { Você pode pesá-los: eles } \\
\text { não dizem nada. } \\
\text { Mas continuam lá, } \\
\text { sempre frios, sempre impassíveis. }\end{array}$ \\
\hline $\begin{array}{l}\text { Det er dei som veit } \\
\text { kva tingi veg. }\end{array}$ & $\begin{array}{l}\text { São eles que sabem } \\
\text { quanto as coisas pesam. }\end{array}$ \\
\hline
\end{tabular}




\begin{tabular}{|l|l|}
\hline Eg stend eg, seddu & Eu estou aqui, sabe \\
Eg stend eg, seddu. & Eu estou aqui, sabe. \\
Eg stod her i fjor òg eg, seddu. & Eu estava aqui no ano passado, sabe. \\
Eg kjem til å stå her eg, seddu. & Eu vou continuar aqui, sabe. \\
Eg tek det eg, seddu. & Eu vou levando, sabe. \\
Du veit ikkje noko du, seddu. & Você não entende nada, sabe. \\
Du er nyss komen du, seddu. & Você acabou de chegar, sabe. \\
Kor lenge skal me stå her? & Quanto tempo a gente vai ficar aqui? \\
Me fær vel eta, seddu. & A gente precisa comer, sabe. \\
Eg stend når eg et òg eg, seddu. & Eu estou aqui também quando como, \\
Og kastar fatet i veggen. & sabe. \\
Me fær vel kvila, seddu. & E atiro o prato na parede. \\
Me fær vel sova, seddu. & A gente precisa descansar, sabe. \\
Me fær vel pissa og skita òg, seddu. & A gente precisa dormir, sabe. \\
& A gente também precisa mijar e cagar, \\
Kor lenge skal me stå her? & sabe. \\
Eg stend eg, seddu. & Quanto tempo a gente vai ficar aqui? \\
Eg tek det eg, seddu. & Eu estou aqui, sabe. \\
Eg kjem til å stå her, eg, seddu. & Eu vou levando, sabe. \\
& Eu vou continuar aqui, sabe. \\
\hline
\end{tabular}




\begin{tabular}{|l|l|}
\hline Kom ikkje med heile sanningi & Não venha com toda a verdade \\
$\begin{array}{l}\text { Kom ikkje med heile sanningi, } \\
\text { kom ikkje med havet for min torste, } \\
\text { kom ikkje med himmelen når eg bed um } \\
\text { ljos, } \\
\text { men kom med ein glimt, ei dogg, eit } \\
\text { fjom, } \\
\text { slik fuglane ber med seg vassdroppar fråo venha com o céu quando peço luz, } \\
\text { lauget } \\
\text { og vinden eit korn av salt. }\end{array}$ & $\begin{array}{l}\text { Não venha com o mar para a minha sede, } \\
\text { nada, } \\
\text { como os pássaros levam gotas d'água ao } \\
\text { sair do banho } \\
\text { e o vento um grão de sal. }\end{array}$ \\
\hline
\end{tabular}




\begin{tabular}{|l|l|}
\hline Lat meg gjera som tordivelen & Quero fazer como o rola-bosta \\
Sorgene legg seg yver meg & Tristezas caem em cima de mim \\
og klemmer meg ned i ei varm boslege. & e me espremem sob a sujeira quente. \\
Lat meg likevel røra på meg, & Mesmo assim quero abrir espaço, \\
prøva kreftene, letta på torvone - & testar minhas forças, procurar terra - \\
lat meg gjera som tordivelen & quero fazer como o rola-bosta \\
når han ein vårdag grev seg ut or myk- & quando na primavera saiu do esterco. \\
dungen. & \\
\hline
\end{tabular}




\begin{tabular}{|c|c|}
\hline Bruvekti & A balança \\
\hline Det er den gamle bruvekti & É a velha balança \\
\hline som er det viktigaste & o mais importante \\
\hline på bui her & aqui no galpão \\
\hline (og so eg sjølv då), & (e eu também, claro), \\
\hline difor har ho plassen sin & por isso ela fica \\
\hline midt på golvet, det & bem no meio, é \\
\hline er ho som slær fast & ela que determina \\
\hline tyngdi og avgjer & o peso e decide \\
\hline kva frakti vert. & o valor do frete. \\
\hline Rett nok kjenner eg & Ao pegar em sacos e caixas \\
\hline når eg tek i kassar og sekker & eu sei muito bem \\
\hline kor tunge dei er, & quanto pesam, \\
\hline men dei lyt på vekti & mas todos vão à balança, \\
\hline so ho fær segja sitt. & que então diz o que pensa. \\
\hline Me tingar oss imillom & Negociamos um pouco \\
\hline med eg set på loddi, & enquanto eu ponho os pesos, \\
\hline og vert som oftast & e em geral chegamos \\
\hline samde,- ho vippar, & a um acordo - ela oscila, \\
\hline eg nikkar, & eu concordo, \\
\hline og me segjer & e dizemos, \\
\hline det stemmer, - me & “está certo” - não \\
\hline tek det ikkje so på grammet. & discutimos as gramas. \\
\hline Vekti er rusta, og eg & A balança está enferrujada, e eu \\
\hline er stiv i ryggen av gikt, & tenho reumatismo nas costas, \\
\hline som vel er, er loddi lettare & mas por sorte os pesos são mais \\
\hline enn det eg veg. & leves do que aquilo que peso. \\
\hline Stundom merkar eg at folk tvilar på & Às vezes noto que as pessoas duvidam \\
\hline um eg veg rett. & da minha pesagem. \\
\hline Folk er rare. & As pessoas são estranhas. \\
\hline Skal dei selja noko, & Se querem vender, \\
\hline skal det vera tungt, & querem pesos altos, \\
\hline skal dei senda noko, & Se querem mandar, \\
\hline skal det vera lett. & querem pesos baixos. \\
\hline
\end{tabular}




\begin{tabular}{|c|c|}
\hline Skrivaren var inne her ein dag, & O juiz passou aqui um dia desses, \\
\hline han furda òg på vekti, kom vel & e também se admirou com a balança, \\
\hline i hug det han sjølv & sem dúvida cioso \\
\hline har å vega. & do que tem a pesar. \\
\hline «Det er ingi apotekarvekt,» sa eg, & $\begin{array}{l}\text { "Não é uma balança de farmácia", eu } \\
\text { disse, }\end{array}$ \\
\hline men tenkte helst på ei vekt eg såg & pensando na balança que vi \\
\hline hjå ein gullsmed ein gong, & certa vez num ourives, \\
\hline han vog gullstøv & que pesava pó de ouro \\
\hline med pinsett. & com uma pinça. \\
\hline Eg har elles ofte tenkt på det & Muitas vezes penso nas coisas \\
\hline ein skrivar har å vega: & que um juiz tem a pesar: \\
\hline Rett og urett, & Justiça e injustiça, \\
\hline straff og bøter, & penas e multas, \\
\hline liv og lagnader. & vidas e destinos. \\
\hline Kven justerar & Quem confere \\
\hline dei loddi, & esses pesos, \\
\hline den vekti? & essa balança? \\
\hline
\end{tabular}




\begin{tabular}{|c|c|}
\hline Yver Hengjemyri & Travessia do pântano \\
\hline $\begin{array}{l}\text { Det er rotstokkane av alle trei som har } \\
\text { stupt uti her, som gjer du kan gå } \\
\text { trygt yver myri. } \\
\text { Slike stokkar held seg lenge, dei kan } \\
\text { ha lege her i hundratals år, } \\
\text { og endå er det eit morke skrimsel } \\
\text { att av dei under mosen, } \\
\text { dei er enno med og ber } \\
\text { so du kjem frelst yver. } \\
\text { Og når du skyv ut på fjellvatnet, } \\
\text { kjenner du at minnet um den kaldingen } \\
\text { som drukna seg her ein gong, } \\
\text { er med og ber den skrale pråmen. } \\
\text { Han, den galningen, trudde livet sitt } \\
\text { til vatnet og æva. }\end{array}$ & $\begin{array}{l}\text { São os troncos das árvores caídas } \\
\text { aqui que permitem atravessar } \\
\text { o pântano em segurança. } \\
\text { Os troncos resistem muito, podem } \\
\text { estar aqui há séculos, } \\
\text { e assim mesmo vestígios escuros } \\
\text { permanecem sob o musgo, } \\
\text { continuam aqui e aguentam } \\
\text { para que você atravesse a salvo. } \\
\text { Ao navegar pelo lago da montanha, } \\
\text { você sente que a memória do coitado } \\
\text { que outrora se afogou por aqui } \\
\text { acompanha você e carrega o frágil barco. } \\
\text { Ele, num desvario, confiou a vida } \\
\text { à água e à eternidade. }\end{array}$ \\
\hline
\end{tabular}

